\title{
The Effectiveness of Transcranial Brain Stimulation in Improving Clinical Signs of Hyperkinetic Movement Disorders
}

\author{
Ignacio Obeso ${ }^{1,2 *}$, Antonio Cerasa ${ }^{3}$ and Aldo Quattrone ${ }^{3,4}$ \\ ${ }^{1}$ Centro Integral en Neurociencias A. C. (CINAC), HM Hospitales - Puerta del Sur. Móstoles, Madrid, Spain, ${ }^{2}$ Center for \\ Networked Biomedical Research on Neurodegenerative Diseases, Madrid, Spain, ${ }^{3}$ Neuroimaging Research Unit, Institute of \\ Molecular Bioimaging and Physiology - National Research Council, Germaneto, Italy, ${ }^{4}$ Neurology Unit, Institute of Neurology, \\ University "Magna Graecia", Catanzaro, Italy
}

\section{OPEN ACCESS}

Edited by:

Wendy Noble,

King's College London, UK

Reviewed by:

Carmelo Mario Vicario,

Bangor University, UK Chrystalina A. Antoniades,

University of Oxford, UK

*Correspondence: Ignacio Obeso

i.obesomartin@gmail.com

Specialty section:

This article was submitted to

Neurodegeneration

a section of the journal

Frontiers in Neuroscience

Received: 28 September 2015 Accepted: 07 December 2015 Published: 07 January 2016

Citation:

Obeso I, Cerasa A and Quattrone A (2016) The Effectiveness of Transcranial Brain Stimulation in Improving Clinical Signs of Hyperkinetic Movement Disorders.

Front. Neurosci. 9:486.

doi: 10.3389/fnins.2015.00486
Repetitive transcranial magnetic stimulation (rTMS) is a safe and painless method for stimulating cortical neurons. In neurological realm, rTMS has prevalently been applied to understand pathophysiological mechanisms underlying movement disorders. However, this tool has also the potential to be translated into a clinically applicable therapeutic use. Several available studies supported this hypothesis, but differences in protocols, clinical enrollment, and variability of rTMS effects across individuals complicate better understanding of efficient clinical protocols. The aim of this present review is to discuss to what extent the evidence provided by the therapeutic use of rTMS may be generalized. In particular, we attempted to define optimal cortical regions and stimulation protocols that have been demonstrated to maximize the effectiveness seen in the actual literature for the three most prevalent hyperkinetic movement disorders: Parkinson's disease (PD) with levodopa-induced dyskinesias (LIDs), essential tremor (ET) and dystonia. A total of 28 rTMS studies met our search criteria. Despite clinical and methodological differences, overall these studies demonstrated that therapeutic applications of rTMS to "normalize" pathologically decreased or increased levels of cortical activity have given moderate progress in patient's quality of life. Moreover, the present literature suggests that altered pathophysiology in hyperkinetic movement disorders establishes motor, premotor or cerebellar structures as candidate regions to reset cortico-subcortical pathways back to normal. Although rTMS has the potential to become a powerful tool for ameliorating the clinical outcome of hyperkinetic neurological patients, until now there is not a clear consensus on optimal protocols for these motor disorders. Well-controlled multicenter randomized clinical trials with high numbers of patients are urgently required.

Keywords: rTMS, Parkinson's disease, levodopa-induced dyskinesias, essential tremor, dystonia

\section{INTRODUCTION}

Alteration in dynamics of neural connectivity is the hallmark of motor and behavioral disease in humans. Brain connectivity affected by functional deficits will either produce exacerbated or reduced brain signal and thus the observed clinical symptomatology. In the motor domain, presence of hyperkinetic movement disorders is typically manifested as increased muscular activity 
that leads to involuntary and unwanted movements, abnormal postures or combination of both. These are present in several neurological disorders, such as essential tremor (ET), dystonia, and Parkinson's disease (PD). In contrast, hypokinetic movement disorders represent loss of vigor and movement that produces rigidity and the inability to initiate and terminate actions efficiently, present in bradykinesia or freezing of gait in PD. Current treatments are mainly pharmacological, but recently functional surgery has made progress in remediation of uncontrolled and unwanted motor disorders (Fasano and Lozano, 2015).

The basal ganglia are considered the main neurodegenerative site of hyper- and hypo-kinetic movement (Middleton and Strick, 2000; Hamani et al., 2004). Due to its strict relationship with several brain regions, the basal ganglia are considered the principal hub of the neural pathways involved in motor control, which included other regions such as the subthalamic nucleus (STN), globus pallidum (GP), thalamus, together with the supplementary motor area (SMA), motor cortex (M1), and frontal regions (Alexander et al., 1986; Kehagia et al., 2013). In the last few years, advances in the neurophysiological and neuroimaging fields have provided alternative scenarios for understanding the neurobiological mechanisms of motor disorders. Indeed, several lines of evidence support the notion that others structures, outside traditional striato-thalamo-cortical pathways, are strongly involved. In particular, the cerebellothalamic circuitry (Pinto et al., 2003; Lehéricy et al., 2013) as well as intra-cortical connections between the premotor cortex and the inferior frontal cortex (IFC), would seem to play a key role in the dysfunctional pathophysiological model of some hyperkinetic motor disorders (Herz et al., 2014; Cerasa et al., 2015).

When traditional treatments fail or do not reach the expected motor benefit, it is now possible to modulate the pathological level of cortical activity using invasive methods such as deep brain stimulation (Diamond and Jankovic, 2005). However, considerable effort is being made on applying other methods that are non-invasive, less costly, and capable of producing beneficial effects in the long-term. The increasing number of research and clinical protocols using non-invasive brain stimulation protocols in patients with neurological conditions show intermixed effects and reports. To date, therapeutic trials using repetitive transcranial magnetic stimulation (rTMS) in PD, ET or dystonia have reported some controversial findings. The use of inhibitory brain stimulation to reduce excessive and abnormal cortical activity in hyperkinetic motor disorders is a potential tool to remediate motor control, posture, muscle tone, and cognitive problems, but considerable effort is needed to test the multiple available protocols when using brain stimulation tools in neurological patients (Ridding and Rothwell, 2007; Elahi et al., 2009).

The present review aims to focus on studies using transcranial brain stimulation protocols to modulate hyperkinetic neurological disorders aimed at clarifying the optimal conditions in which non-invasive stimulation may be used in movement disorders. We selected studies with constrained search in PubMed and Medline using as search terms: dyskinesias, dystonia, and ET in combination with widely used brain stimulation terms: TMS, rTMS, and TBS, from inception to September 25, 2015. Publication lists of relevant studies were later scanned for potential eligible articles. We summarize key technical aspects of rTMS with effective results for PD, ET, and dystonia to propose focused research plans to increase the positive impact of non-invasive brain stimulation in clinical practice.

\section{rTMS Protocol for Therapeutic Purpose}

rTMS has effects on the brain and behavior that outlast the period of stimulation due to plastic changes of long-term potentiation or depression in synaptic connections amongst cortical networks. Regions or networks with suboptimal functioning after brain damage or neurodegenerative disease are potential candidates for neuromodulation therapy. So far, the therapeutic use of rTMS has been proved effective in patients with major depression refractory to regular treatment (George et al., 2013). In neurological realm, movement disorders has received much attention with regard to rTMS therapeutic studies. However, experiments in healthy subjects suggest that rTMS protocols have short-lived aftereffects. Hence, clinical neuroscience encounters a challenge with aim boosting longer time-periods of beneficial effects in patient's quality of life.

Despite illness, several rTMS protocols may be used for therapeutic purpose (for review see Ridding and Rothwell, 2007). The key aspect to consider is how to prolong rTMS positive effects in clinical conditions and quality of life. Current rTMS protocols apply low frequency $(<1 \mathrm{~Hz})$ or high frequency $(>1 \mathrm{~Hz})$, as well as single rTMS or multiple rTMS sessions. Generally, high frequency stimulation induces an increase in cortical excitability and low frequency stimulation causes a decrease in cortical excitability. To benefit plastic and long-term rTMS potentiation, multiple sessions tend to show stronger and cumulative effects in clinical and behavioral measures. An alternative use of rTMS is theta burst stimulation (TBS), consisting of short, repeated bursts of TMS pulses at $50 \mathrm{~Hz}$ (Huang et al., 2005). Again, the use of TBS allows decrease (using continuous TBS) or increase (using intermittent TBS) of cortical excitability using different sets of magnetic trains.

The fact that cortical baseline activity may be either hyperexcitable or hypoexcitable has formed the idea of using low-frequency rTMS to treat disorders with marked cortical hyperexcitability, while using high frequency rTMS in conditions with low cortical excitability. For this reason, in hyperkinetic motor disorders the rationale behind the application of rTMS protocol is to reduce abnormal cortical hyperexcitability, although this is not true in all the circumstances as it depends on several methodological and clinical factors, discussed in the present review.

\section{THERAPEUTIC POTENTIAL OF rTMS IN PARKINSON'S DISEASE PATIENTS}

PD is primarily a disorder of response initiation characterized by an excessive motor inhibition. In particular, bradykinesia (slowness of voluntary movements), tremor, rigidity, and gait problems are cardinal motor signs in PD, greatly improved by 
treatments with dopamine replacement therapy. However, PDrelated neurochemical changes are long-lasting and difficult to contrast by pharmacological interventions. For this reason, new treatment strategies have been proposed. rTMS has been studied as an intervention to ameliorate motor symptoms (Edwards et al., 2008; Elahi et al., 2009), including rigidity and bradykinesia, motor complications of therapy (e.g., dyskinesias) and nonmotor symptoms, mainly depression and speech (Lefaucheur et al., 2004). Despite a large heterogeneity among these studies (Koch, 2013), it was proposed that high frequency rTMS (i.e., $5 \mathrm{~Hz}$ ) applied over M1 could turn as a gold-standard use in PD to significantly reduce motor signs as measured by UPDRS-III (Elahi et al., 2009). Moreover, the diverse results provided by the literature indicate updating in future interventions, which will necessitate separation of PD motor signs in an attempt to separate the diverse pathophysiology present in tremor, bradykinesia, rigidity, and gait problems. In case where such separation turns successful, perhaps we could foresee new ways of understanding and treating PD symptoms alternatively.

\section{rTMS in Parkinson's Disease Patients with Levodopa-Induced Dyskinesias}

Nowadays, treating secondary motor signs related to $\mathrm{PD}$ treatments is a possibility based on clear pathophysiological models to reach effective targets. Despite pharmacological or non-pharmacological interventions, after 4-6 years of levodopa therapy, a significant proportion of patients exhibit a decline in the therapeutic efficacy of levodopa and develop disabling motor symptoms, termed levodopa-induced dyskinesias (LIDs). The time-to-onset and severity of this motor complication show large individual variability thus limiting the long-term use of levodopa and clinical strategies aimed at reducing LIDs manifestation.

In the last few years, a considerable effort has been made to understand the neurobiological basis of this motor complication. LIDs are classically ascribed to the degree of nigrostriatal neurodegeneration and striatal changes associated with chronic levodopa therapy (Obeso et al., 2000). These interact to induce maladaptive striatal plasticity, which has the effect of altering neuronal activity in striato-pallidal circuits. The pioneering works of Rascol et al. (1998) and Brooks et al. (2000) demonstrated in vivo that these abnormal neuronal firing patterns extended on the brain cortex mainly including the sensorimotor areas of the cortico-basal ganglia loop.

After these first functional neuroimaging studies, for a long time no additional neuroimaging investigations have been performed on LIDs patients. From 2010 to date, new functional and structural neuroimaging studies have shed new light on the pathophysiological mechanisms underlying LIDs suggesting that that LIDs-related symptoms may originate in brain network beyond the "classical" basal ganglia dysfunctional model, including cortical regions strongly involved in motor inhibition processes. Indeed, what has clearly been demonstrated was that PD patients with LIDs are characterized by dysfunctional coupling between the prefrontal cortex, including the right IFC and the SMA and basal ganglia measured at rest (Cerasa et al., 2015), during a simple finger-tapping task (Cerasa et al., 2012) or during a GoNo-Go task (Herz et al., 2014, 2015). Moreover, these functional abnormalities in LIDs patients were also mirrored by abnormal anatomical changes detected in the SMA and IFC (Cerasa et al., 2011, 2013a,b). These findings have already raised an interesting scientific debate on the toxic effects of levodopa on brain morphometry (Vernon and Modo, 2012; Cerasa et al., 2014) and on the hypothetical role of the prefrontal cortex as a new target for brain stimulation useful to decrease the severity of LIDs (Cerasa and Quattrone, 2014a,b; Obeso and Strafella, 2014a,b; Rothwell and Obeso, 2015), seen to improve motor inhibition due to compensatory processes of interconnected regions (Obeso et al., 2013; Zandbelt et al., 2013).

Indeed, to treat secondary effects of principal treatments in PD such as LIDs is also an actual necessity and priority. Guided by imaging results, rTMS over regions showing functional overactivity in LIDs was reported either over the SMA (Koch et al., 2005; Brusa et al., 2006) or over the IFC (Cerasa et al., 2015) (Table 1). Otherwise, no significant or moderate effects emerged when TMS protocol was applied over the primary motor cortex (Wagle-Shukla et al., 2007; Filipovic et al., 2009; Kodama et al., 2011; Filipović et al., 2013; Cerasa et al., 2015). In particular, the Koch's group was the first in using rTMS approach with therapeutical purpose (Koch et al., 2005). In 2005, they demonstrated that one single session of rTMS at low frequency $(1 \mathrm{~Hz})$ over the SMA produced significant motor improvements in eight patients with LIDs. The rationale behind the choice to stimulate SMA is based either on previous neuroimaging findings describing functional overactivity in this region (Rascol et al., 1998; Brooks et al., 2000) or on the notion that repeated sessions of premotor cortex stimulation induces cumulative changes in the excitability over the primary motor cortex (Bäumer et al., 2003). With this in mind, Brusa et al. (2006) tried to translate this single TMS protocol in a prolonged therapeutic session (5 days), failing to demonstrate a clear beneficial effect. Contrarily, prolonged session (2 weeks) applied on the bilateral cerebellar cortex using high frequency $(50 \mathrm{~Hz})$ cTBS, showed persistent clinical beneficial effects in LIDs patients for up to 4 weeks (Koch et al., 2009). To explain this discrepancy, these authors proposed that this might be dependent upon the fact that the cerebellum has greater plastic mechanisms involved in motor learning (Ito, 2008) compared to SMA and therefore could be susceptible to more sustained rTMS-induced changes, thus leading to marked clinical beneficial effects. Moreover, recent evidence suggested a causal role of the effective cerebello-cortical connectivity in motor inhibition (Picazio and Koch, 2015), a cognitive domain strongly involved in the pathophysiological mechanisms of LIDs (Cerasa et al., 2015). The intimate link between motor inhibition and LIDs has also been confirmed in a recent study (Cerasa et al., 2015) where it was demonstrated that a single session of continuous but not intermittent or sham TBS applied over the right IFC was able to significantly reduce the amount of dyskinesias as measured by the conventional abnormal involuntary movement scale (AIMS).

The primary goal of the motor inhibition system (mainly composed by STN, basal ganglia, SMA, and IFC) is to control/modulate the primary motor output pathway. Idiopathic PD is primarily a disorder of response initiation characterized by an excessive motor inhibition (i.e., akinesia, bradykinesia), 
TABLE 1 | rTMS application on PD with LIDs.

\begin{tabular}{|c|c|c|c|c|}
\hline References & Sample & TMS protocol & $\begin{array}{l}\text { Anatomical } \\
\text { localization }\end{array}$ & Main findings \\
\hline \multirow[t]{2}{*}{ Koch et al., 2005} & 8 Dyskinetic PD & $\begin{array}{l}\text { Single Session rTMS train at } 1 \mathrm{~Hz} \\
\text { or } 5 \mathrm{~Hz}\end{array}$ & SMA & $\begin{array}{l}\text { Single Session Low frequency }(1 \mathrm{~Hz}) \text { : reduced } \\
\text { AIMS after } 15 \mathrm{~min}\end{array}$ \\
\hline & & & & $\begin{array}{l}\text { Single Session High frequency }(5 \mathrm{~Hz}) \text { : induced } \\
\text { a slight but not significant effect }\end{array}$ \\
\hline \multirow[t]{2}{*}{ Brusa et al., 2006} & 10 Dyskinetic PD & $\begin{array}{l}\text { Single and Prolonged ( } 5 \text { days) } \\
\text { sessions rTMS train at } 1 \mathrm{~Hz}\end{array}$ & SMA & $\begin{array}{l}\text { Single Session Low frequency }(1 \mathrm{~Hz}) \text { : reduced } \\
\text { AIMS and improved UPDRS scores after } 15 \mathrm{~min}\end{array}$ \\
\hline & & & & $\begin{array}{l}\text { Prolonged Session Low frequency }(1 \mathrm{~Hz}) \text { : failed } \\
\text { to enhance beneficial effects }\end{array}$ \\
\hline Wagle-Shukla et al., 2007 & 6 Dyskinetic PD & $\begin{array}{l}\text { Prolonged ( } 2 \text { weeks) sessions } \\
\text { rTMS train at } 1 \mathrm{~Hz}\end{array}$ & M1 & $\begin{array}{l}\text { Prolonged Session Low frequency }(1 \mathrm{~Hz}) \text { : } \\
\text { induced a slight but not significant effect }\end{array}$ \\
\hline Filipovic et al., 2009 & 10 Dyskinetic PD & $\begin{array}{l}\text { Prolonged ( } 4 \text { days) sessions } \\
\text { rTMS train at } 1 \mathrm{~Hz}\end{array}$ & M1 & $\begin{array}{l}\text { Prolonged Session Low frequency }(1 \mathrm{~Hz}) \text { : } \\
\text { induced a modest beneficial effect }\end{array}$ \\
\hline \multirow[t]{2}{*}{ Kodama et al., 2011} & $\begin{array}{l}\text { Case Report PD with painful } \\
\text { off-period dystonia }\end{array}$ & $\begin{array}{l}\text { Single Session rTMS train at } \\
0.9 \mathrm{~Hz}\end{array}$ & M1 & $\begin{array}{l}\text { Single Session Low frequency over M1: } \\
\text { reduced painful dystonia and walking } \\
\text { disturbances }\end{array}$ \\
\hline & & & SMA & $\begin{array}{l}\text { Single Session Low frequency over SMA: } \\
\text { induced no significant effects }\end{array}$ \\
\hline Filipović et al., 2013 & $\begin{array}{l}\text { Case Report PD with diphasic } \\
\text { dyskinesia }\end{array}$ & $\begin{array}{l}\text { Prolonged ( } 4 \text { days) sessions } \\
\text { rTMS train at } 1 \mathrm{~Hz}\end{array}$ & M1 & $\begin{array}{l}\text { Prolonged Session Low frequency }(1 \mathrm{~Hz}) \text { : } \\
\text { yielded beneficial effects in the upper limb }\end{array}$ \\
\hline Koch et al., 2009 & 10 Dyskinetic PD & $\begin{array}{l}\text { Prolonged ( } 2 \text { weeks) sessions } \\
\text { cTBS } 3 \text { pulse bursts at } 50 \mathrm{~Hz}\end{array}$ & Cerebellum & $\begin{array}{l}\text { Prolonged Session High frequency }(50 \mathrm{~Hz}) \text { : } \\
\text { yielded beneficial effects }\end{array}$ \\
\hline \multirow[t]{2}{*}{ Cerasa et al., 2015} & 11 Dyskinetic PD & $\begin{array}{l}\text { Single Session cTBS } 3 \text { pulse } \\
\text { bursts at } 50 \mathrm{~Hz}\end{array}$ & $\begin{array}{l}\text { Right Inferior } \\
\text { Frontal Cortex }\end{array}$ & $\begin{array}{l}\text { Single Session High frequency }(50 \mathrm{~Hz}) \text { : reduced } \\
\text { AIMS after } 45 \mathrm{~min}\end{array}$ \\
\hline & & & M1 & $\begin{array}{l}\text { Single Session High frequency }(50 \mathrm{~Hz}) \text { : failed to } \\
\text { enhance beneficial effects }\end{array}$ \\
\hline
\end{tabular}

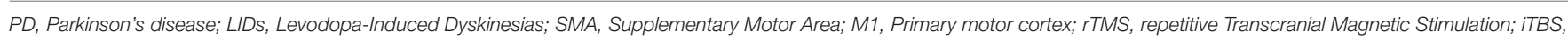
intermittent theta burst Transcranial Magnetic Stimulation; cTBS, continuous theta burst Transcranial Magnetic Stimulation; AIMS, Abnormal Involuntary Movement Scale.

whereas LIDs are clearly a clinical expression of disinhibition of movement. For this reason, the recent neuroimaging evidence strongly supports the idea that dysfunctions of the primary motor system in LIDs patients are related to that of motor inhibition pathway. However, it remains to be clarified why clinical beneficial effects are evident after rTMS over the cortical regions involved in the motor inhibition system (SMA and IFC), whereas brain stimulation on the primary motor cortex produced conflicting results (Wagle-Shukla et al., 2007). Indeed, WagleShukla et al. (2007), using a prolonged session (2 weeks) of low frequency $(1 \mathrm{HZ})$ rTMS over the primary motor cortex, did not report evident clinical improvements in $6 \mathrm{PD}$ patients with LIDs. This preliminary evidence has also been confirmed in a recent study (Cerasa et al., 2015), despite the employment of a different TMS protocol [single session high-frequency $(50 \mathrm{~Hz})$ cTBS]. Three additional studies, otherwise, reported moderate evidence about the role of the primary motor cortex as potential stimulation site for LID treatment. First, Filipovic et al. (2009), using low-frequency rTMS $(1 \mathrm{~Hz})$ for 4 consecutive days in 10 PD patients with LIDs, reported residual beneficial clinical effects in dyskinesia severity. With the same TMS protocol, these authors found an increased beneficial effect also in one PD patient with diphasic dyskinesia, which is far less studied than more common peak-of-dose dyskinesias (Filipović et al., 2013). Finally, in another case report, $0.9 \mathrm{~Hz}$ rTMS over primary motor area significantly reduced the painful dystonia and walking disturbances in one dyskinetic patient with painful off-period dystonia (Kodama et al., 2011).

To sum up, the current literature on therapeutic trials of rTMS in PD patients with LIDs is in its relative infancy, and nowadays there is insufficient information to support evidence-based clinical protocols. However, the search for the most effective protocol leads us to the conclusion that brain stimulation on cortical regions part of the motor inhibition network (IFC, SMA, and cerebellum) might be highly promising as therapeutical sites for treatment of LID. Otherwise, evidence provided by rTMS over the primary motor cortex requires further confirmation. Indeed, while in idiopathic PD a plethora of studies demonstrated the beneficial effects on motor symptoms after high-frequency stimulation of the primary motor cortex (Edwards et al., 2008), in dyskinetic patients the high clinical heterogeneity, as well as variability in TMS protocols prevents us from making a general 
conclusion about these findings. The lack of consistency is also dependent upon the fact that advanced neuroimaging has not yet clarified how levodopa influences neurofunctional activity in the motor cortex.

\section{THE POTENTIAL USE OF rTMS TO TREAT DYSTONIA}

Dystonia is a hyperkinetic movement disorder mainly characterized by excessive and painful muscle contraction producing muscle twists, abnormal posture, and inefficient moves. Body limbs involved in such muscles alteration classify the diverse types of dystonia. Focal dystonia are those where abnormal participation of muscles and gestures give raise to painful postures within an isolated body region. Meanwhile, segmental dystonia must involve two or more adjacent body regions and generalized dystonia, which affects upper and lower limbs of the body (Marsden, 1976). According to its etiology, dystonia can be divided into primary dystonia, dystonia plus syndrome or secondary dystonia (Marsden, 1976). Primary dystonia corresponds to those patients showing no brain lesions as revealed by structural MRI scans. It is well known that primary dystonia can be task-specific, altering movements involved in fine motor control (such as writer's cramp), speaking (dysphonia), playing piano, or running (Breakefield et al., 2008). This dystonia form may be idiopathic or genetic, based on a variety of more than 30 genes involved in the disease (Bragg et al., 2011). Secondary dystonia results from stroke or traumatic brain injury or induced by certain treatments thus has a certain origin. However, the causes of most dystonia are unknown but some monogenic subtype alterations (in DYT1, DYT6, or DYT13) are considered potentially relevant in developing dystonic motor symptoms (Bragg et al., 2011).

Considering the etiology heterogeneity in dystonia, its pathophysiological model may vary across dystonia subtypes. Based on clinico-pathological studies in patients with symptomatic dystonia (Marsden et al., 1985) and intracranial recordings from the GPi and thalamus (Vitek et al., 1999; Zhuang et al., 2004), dystonia is considered a basal ganglia disorder (Berardelli et al., 1998; Zheng et al., 2012). Indeed, DBS produces a significant positive response over the GPi (Vidailhet et al., 2005) and reduces metabolic activity over important cortical regions part of fronto-striatal loops [i.e., the dorsolateral prefrontal cortex (DLPFC) or the orbitofrontal cortex (OFC); Detante et al., 2004]. Recent findings from neuropathological data show in a large cohort of adult and child dystonia significant reductions of substantia nigra neurons as compared to controls (Iacono et al., 2015). This evidence has also been confirmed by positron emission tomography (PET) studies. Indeed, using dopaminergic markers at rest, some groups have pinpointed cell loss over striatal and cortical regions in primary dystonia (Otsuka et al., 1992; Berman et al., 2013). Moreover, increased glucose metabolism over the lentiform nucleus and cortical motor regions including SMA, lateral premotor cortex, anterior cingulate cortex (ACC), and DLPFC have also been reported in primary dystonia (Eidelberg et al.,
1995; Odergren et al., 1998; Ibáñez et al., 1999; Pujol et al., 2000; Oga et al., 2002; Butterworth et al., 2003; Lerner et al., 2004). Functional alterations in dystonic patients were also coupled by underlying anatomical brain abnormalities. Indeed, patients with cervical dystonia, blepharospasm, or writer's cramp are characterized by anatomical changes in the basal ganglia, motor and premotor cortices, cerebellum and SMA (Eidelberg et al., 1995; Berardelli et al., 1998; Draganski et al., 2003; Zheng et al., 2012).

However, dystonia is not only considered to be dependent upon the basal ganglia-thalamo-cortical pathway (Breakefield et al., 2008), but recent evidence strongly highlights the involvement of the cerebellar cortex and its direct connections with the motor cortex (Lehéricy et al., 2013; Neumann et al., 2015). Cerebellar modulation over motor cortex seems to be compromised in dystonia patients and M1 excitability (i.e., intra-cortical facilitation) seems responsive to cerebellar rTMS (Brighina et al., 2009). However, it should bear in mind that although dystonic patients are not characterized by evident cerebellar motor signs (i.e., loss of balance or frequent falling), it has been proposed that the cerebellum in dystonia patients might be involved in compensatory modulation of the abnormal activity detected in the motor cortex, or as a potential effective input to modulate basal ganglia dysfunctional state (Wu and Hallett, 2013). Moreover, previous evidence points to altered cerebellar activation along the inhibitory motor circuits in dystonia (Huang et al., 2011; Koch et al., 2014), thus increasing the probability of such loops as potential candidate for neuromodulation.

The role of cortico-striatal and cerebellar-thalamocortical loops in dystonia, thus support two open accesses to cortical neuromodulation over motor, premotor, or cerebellar targets. The target location problem in dystonia seems rather straightforward based on current pathophysiological knowledge. So far, studies using rTMS to treat dystonia motor signs have reported beneficial clinical effects when targeting stimulation to motor (Odergren et al., 1998; Ibáñez et al., 1999; Pujol et al., 2000; Oga et al., 2002; Butterworth et al., 2003; Lerner et al., 2004; Murase et al., 2005; Allam et al., 2007; Angelakis et al., 2013; Berman et al., 2013) or somatosensory regions (Borich et al., 2009; Havrankova et al., 2010), but less clinical beneficial effects after cerebellar stimulation (Koch et al., 2014; Sadnicka et al., 2014) (see Table 2). Positive and acute effects after cerebellar stimulation in one study (Koch et al., 2014) offer new insights to further assess stimulation protocols with aim maintenance of prolonged positive effects (although not every study assessed long-term effects, Table 2). However, the gold-standard in dystonia seems to be targeting motor regions that produce functional changes over basal ganglia (Bharath et al., 2015).

The apparent efficient parameters to find positive results in dystonia seem to be closely associated to the number of stimulation sessions. Some single session studies have shown effective results (Murase et al., 2005; Tyvaert et al., 2006; Furuya et al., 2014) but are less persistent across time. This single session protocols stimulating premotor regions (at low frequencies) reported motor improvement (hand writing) in focal hand dystonia patients (Siebner et al., 1999; Lefaucheur et al., 2004; 
TABLE 2 | rTMS application on dystonia.

\begin{tabular}{|c|c|c|c|c|}
\hline References & Sample & TMS Protocol & $\begin{array}{l}\text { Anatomical } \\
\text { localization }\end{array}$ & Main findings \\
\hline $\begin{array}{l}\text { Siebner et al., } \\
1999\end{array}$ & 16 WC & $\begin{array}{l}\text { Single session rTMS at } 1 \mathrm{~Hz} \text {, } \\
\text { placebo controlled }\end{array}$ & M1 & $\begin{array}{l}\text { Single session yielded positive results as measured } \\
\text { by pen pressure reductions and self-reported } \\
\text { improvement }\end{array}$ \\
\hline $\begin{array}{l}\text { Lefaucheur } \\
\text { et al., } 2004\end{array}$ & $\begin{array}{l}3 \text { secondary } \\
\text { dystonia }\end{array}$ & $\begin{array}{l}\text { Prolonged sessions ( } 5 \\
\text { consecutive days) rTMS at } 1 \mathrm{~Hz}\end{array}$ & Premotor & $\begin{array}{l}\text { Prolonged session yielded positive results in } \\
\text { movement rating scale and decrease in painful axial } \\
\text { spams }\end{array}$ \\
\hline $\begin{array}{l}\text { Murase et al., } \\
2005\end{array}$ & $9 \mathrm{WC}$ & $\begin{array}{l}\text { Single session (1 day) rTMS at } \\
0.2 \mathrm{~Hz}\end{array}$ & $\begin{array}{l}\text { Premotor } \\
\text { SMA } \\
\text { M1 }\end{array}$ & $\begin{array}{l}\text { Single session yielded positive results over premotor } \\
\text { site, in decrease contraction and pen pressure }\end{array}$ \\
\hline $\begin{array}{l}\text { Tyvaert et al., } \\
2006\end{array}$ & $8 \mathrm{WC}$ & $\begin{array}{l}\text { Single session ( } 1 \text { day) rTMS at } \\
1 \mathrm{~Hz}\end{array}$ & Premotor & $\begin{array}{l}\text { Single session yielded positive results in handwriting } \\
\text { velocity and decreased discomfort }\end{array}$ \\
\hline $\begin{array}{l}\text { Allam et al., } \\
2007\end{array}$ & $\begin{array}{l}1 \text { cervical } \\
\text { dyst. WC }\end{array}$ & $\begin{array}{l}\text { Prolonged sessions ( } 5 \\
\text { consecutive days) rTMS at } 1 \mathrm{~Hz}\end{array}$ & Premotor & $\begin{array}{l}\text { Prolonged session yielded positive results in a single } \\
\text { case study in cervical dystonia }\end{array}$ \\
\hline $\begin{array}{l}\text { Borich et al., } \\
2009\end{array}$ & $\begin{array}{l}6 \mathrm{FHD} \\
9 \mathrm{HC}\end{array}$ & $\begin{array}{l}\text { Prolonged sessions ( } 5 \\
\text { consecutive days) rTMS at } 1 \mathrm{~Hz}\end{array}$ & Premotor & $\begin{array}{l}\text { Prolonged session rTMS yielded reduced cortical } \\
\text { excitability and improved handwriting performance } \\
\text { were observed and maintained at least } 10 \text { days }\end{array}$ \\
\hline $\begin{array}{l}\text { Havrankova } \\
\text { et al., } 2010\end{array}$ & 20 WC & $\begin{array}{l}\text { Prolonged sessions ( } 5 \\
\text { consecutive days) rTMS at } 1 \mathrm{~Hz}\end{array}$ & Somatosensory & $\begin{array}{l}\text { Prolonged sessions yielded positive results in } \\
\text { subjective and objective writing maintained for } \\
\text { 3-week time period }\end{array}$ \\
\hline $\begin{array}{l}\text { Schneider } \\
\text { et al., } 2010\end{array}$ & $\begin{array}{l}5 \mathrm{WC} \\
5 \mathrm{HC}\end{array}$ & $\begin{array}{l}\text { Single session (1 day) rTMS train } \\
\text { at } 5 \mathrm{~Hz} \text { fMRI pre vs. post rTMS }\end{array}$ & Somatosensory & $\begin{array}{l}\text { Single session no effects in frequency discrimination } \\
\text { task in patients linked to decrease in GPi }\end{array}$ \\
\hline $\begin{array}{l}\text { Benninger } \\
\text { et al., } 2011\end{array}$ & $\begin{array}{l}12 \text { FHD }(6 \\
\text { sham) }\end{array}$ & $\begin{array}{l}\text { Prolonged sessions ( } 3 \text { in } 1 \text { week) } \\
\text { Cathodal tDCS }\end{array}$ & $\begin{array}{l}\text { M1 contralateral } \\
\text { to FHD }\end{array}$ & $\begin{array}{l}\text { Prolonged sessions of tDCS yielded no positive } \\
\text { effects in clinical measures nor handwriting and } \\
\text { cortical excitability }\end{array}$ \\
\hline $\begin{array}{l}\text { Kimberley } \\
\text { et al., } 2013\end{array}$ & 12 FHD & $\begin{array}{l}\text { Prolonged session (5 days) at } \\
1 \mathrm{~Hz} \text { rTMS }\end{array}$ & Dorsal premotor & $\begin{array}{l}\text { Prolonged sessions yielded beneficial effects in pen } \\
\text { force at day } 1 \text { and } 5\end{array}$ \\
\hline $\begin{array}{l}\text { Furuya et al., } \\
2014\end{array}$ & $\begin{array}{l}10 \mathrm{FHC} \\
\text { (pianists) } \\
10 \mathrm{HC}\end{array}$ & $\begin{array}{l}\text { Single session of tDCS (cathodal } \\
\text { or anodal over affected or } \\
\text { unaffected side) }\end{array}$ & M1 & $\begin{array}{l}\text { Single session yielded rhythm sequence } \\
\text { improvement using cathodal tDCS over affected } \\
\text { cortex }\end{array}$ \\
\hline $\begin{array}{l}\text { Sadnicka } \\
\text { et al., } 2014\end{array}$ & 10 WC & $\begin{array}{l}\text { Single session anodal tDCS } \\
\text { (sham controlled) }\end{array}$ & Cerebellum & $\begin{array}{l}\text { Single session tDCS revealed no positive effects in } \\
\text { clinical measures }\end{array}$ \\
\hline $\begin{array}{l}\text { Koch et al., } \\
2014\end{array}$ & $\begin{array}{l}18 \text { cervical } \\
\text { dystonia }\end{array}$ & $\begin{array}{l}\text { Prolonged sessions ( } 2 \text { weeks) } \\
\text { cTBS }\end{array}$ & $\begin{array}{l}\text { Bilateral } \\
\text { cerebellum }\end{array}$ & $\begin{array}{l}\text { Prolonged sessions yielded positive acute results } \\
\text { (immediate effect after } 2 \text {-week cTBS) in clinical } \\
\text { scales }\end{array}$ \\
\hline $\begin{array}{l}\text { Bharath et al., } \\
2015\end{array}$ & $\begin{array}{l}19 \mathrm{WC} \\
20 \mathrm{HC}\end{array}$ & $\begin{array}{l}\text { Single session ( } 1 \text { day) rTMS train } \\
\text { at } 1 \mathrm{~Hz} \text {; } \mathrm{fMRl} \text { pre vs. post }\end{array}$ & Premotor & $\begin{array}{l}\text { Single session reduction in left cerebellum, } \\
\text { thalamus, globus pallidus, putamen, bilateral } \\
\text { supplementary motor area, medial prefrontal lobe }\end{array}$ \\
\hline
\end{tabular}

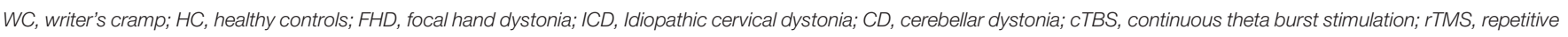

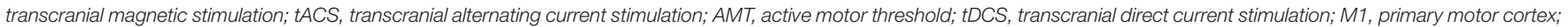
SMA, supplementary motor area.

Murase et al., 2005). Others reported beneficial clinical effects, as measured by subjective clinical evaluations using $1 \mathrm{~Hz}$ rTMS (Murase et al., 2005; Tyvaert et al., 2006), but not always single session turns useful in dystonia (using $5 \mathrm{~Hz}$ rTMS; Schneider et al., 2010). Moreover, single sessions are influenced by patient's expectancy or state-dependent effects. Studies that opted for multiple sessions ( 5 consecutive days) however provide positive and promising results in clinical terms (Lefaucheur et al., 2004; Borich et al., 2009; Angelakis et al., 2013; Kimberley et al., 2013; Koch et al., 2014). Following multiple sessions rTMS, 
TABLE 3 | rTMS application on essential tremor.

\begin{tabular}{|c|c|c|c|c|}
\hline References & Sample & TMS protocol & $\begin{array}{l}\text { Anatomical } \\
\text { localization }\end{array}$ & Main findings \\
\hline \multirow[t]{2}{*}{$\begin{array}{l}\text { Gironell et al., } \\
2002\end{array}$} & $10 \mathrm{ET}$ & $\begin{array}{l}\text { Single sessions ( } 2 \text { days) Active vs. } \\
\text { sham }\end{array}$ & Cerebellum & $\begin{array}{l}\text { Single session acute rTMS beneficial effects on tremor, } \\
\text { dissipated in } 1 \mathrm{~h}\end{array}$ \\
\hline & & rTMS train at $1 \mathrm{~Hz}$ & & \\
\hline \multirow[t]{2}{*}{$\begin{array}{l}\text { Avanzino } \\
\text { et al., } 2009\end{array}$} & $15 \mathrm{ET}$ & Single session & $\begin{array}{l}\text { Right } \\
\text { cerebellum }\end{array}$ & Single session rTMS yielded beneficial effects on tremor \\
\hline & $11 \mathrm{HC}$ & rTMS train at $1 \mathrm{~Hz}$ & & \\
\hline \multirow[t]{2}{*}{$\begin{array}{l}\text { Hellriegel } \\
\text { et al., } 2012\end{array}$} & $10 \mathrm{ET}$ & $\begin{array}{l}\text { Single sessions ( } 2 \text { days) cTBS } 3 \\
\text { pulse bursts at } 50 \mathrm{~Hz}\end{array}$ & Left M1 & $\begin{array}{l}\text { Single session cTBS M1 produced subclinical beneficial } \\
\text { effects }\end{array}$ \\
\hline & $10 \mathrm{HC}$ & 80 vs. $30 \%$ AMT & & \\
\hline \multirow[t]{2}{*}{$\begin{array}{l}\text { Popa et al., } \\
2013\end{array}$} & $11 \mathrm{ET}$ & $\begin{array}{l}\text { Prolonged sessions (5 consecutive } \\
\text { days) }\end{array}$ & $\begin{array}{l}\text { Bilateral } \\
\text { cerebellum }\end{array}$ & $\begin{array}{l}\text { Prolonged Session rTMS yielded beneficial effects on } \\
\text { tremor during } 3 \text { weeks }\end{array}$ \\
\hline & & rTMS train at $1 \mathrm{~Hz}$ & & \\
\hline $\begin{array}{l}\text { Chuang et al., } \\
2014\end{array}$ & $\begin{array}{l}13 \mathrm{ET} \\
18 \mathrm{HC}\end{array}$ & $\begin{array}{l}\text { Single sessions ( } 3 \text { days) cTBS } 3 \\
\text { pulse bursts at } 50 \mathrm{~Hz}\end{array}$ & $\begin{array}{l}\text { M1, premotor } \\
\text { and sham }\end{array}$ & $\begin{array}{l}\text { Single session cTBS modulated cortical excitability for } \\
\text { shorter duration in ET patients }\end{array}$ \\
\hline
\end{tabular}

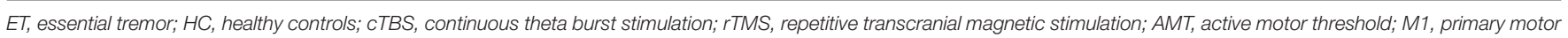
cortex.

plastic changes in dystonic patients lasted 10 days post-treatment (Borich et al., 2009) and importantly, subjective perception of well-being was maintained for a 3-week period (Havrankova et al., 2010). Others reported only acute amelioration of dystonic signs after cTBS, however after cerebellar stimulation (Koch et al., 2014) thus suggesting premotor regions as responsive for multiple neuromodulation sessions in dystonia.

Regarding rTMS stimulation protocols, the disparity in frequency of stimulation (i.e., low vs. high frequencies) is a solid factor of variability in the current literature. Most of the available literature reports low frequencies (see Table 3), although higher ones, i.e., cTBS, do produce enhanced clinical effects. In Koch et al. (2014), 2-week of TBS applied bilaterally over the cerebellum was compared against a sham TBS condition. Patients under the active stimulation showed ameliorated clinical conditions acutely, but not persistently, with a marked decrease in muscle contraction evaluated by a blinded neurologist. In a similar protocol, following $1 \mathrm{~Hz}$ rTMS applied over the left somatosensory parietal region in WC patients (Havrankova et al., 2010), patients showed subjective and objective improvements in writing quality during a 3-week time period. Similarly, using $1 \mathrm{~Hz}$ rTMS over dorsal premotor area produced positive results in pen force use and general patients mobility (Kimberley et al., 2013). Such increment in patients response to rTMS may be driven by the fact that low frequency rTMS seems to modulate somatosensory integration in patients with dystonia and WC (Bäumer et al., 2007). Thus, the working hypothesis is that use of repeated sessions may induce cortical plasticity that induces facilitation of sensory outputs or facilitation of contralateral hemisphere (Bharath et al., 2015) to control motor functions. Further evidence is urgently needed to confirm the use of multiple rTMS sessions and to determine ways of prolonging its duration.
Stimulation over cortical premotor and motor regions connecting with basal ganglia renders a potential treatment in dystonia characterized by functional and compensatory changes in the subcortical regions. Still, greater accuracy in the protocols used to induce subcortical changes are needed. TMS studies trying to induce enhancement of dystonic signs have mostly tackled regions part of the basal ganglia motor loops, i.e., motor, premotor, SMA, and somatosensory regions. The necessity to test alternative TMS protocols under different dystonic symptoms or use stimulation techniques in combination with medication or rehabilitation is obvious.

\section{TURNING DOWN HYPERACTIVE CEREBELLO-THALAMIC LOOPS IN ESSENTIAL TREMOR WITH rTMS}

ET is a hyperkinetic motor disorder that affects one or more body parts by inducing involuntary and rhythmic movements. This may occur in a single limb or at any body part, such as a chin or head with larger prevalence in upper limbs (Helmich et al., 2013). Typically, is presented while moving, bilaterally or kinetic tremor that is visible and persistent. Today, the use of pharmacological in treatment of ET remains poor and unsatisfactory (Louis, 2015). In contrast, surgical treatment is effective in reducing hand tremor in $95 \%$ of patients and improved function in $74 \%$, however with added potential risks being an invasive approach (Sandvik et al., 2012).

ET has been associated with altered oscillatory activity in the motor loop involving the cerebello-thalamo-cortical network (Pinto et al., 2003). Several imaging and animal evidence are in keeping with this view of the disease. Indeed, dysfunctional activities (measured as fMRI or PET) and anatomical changes 


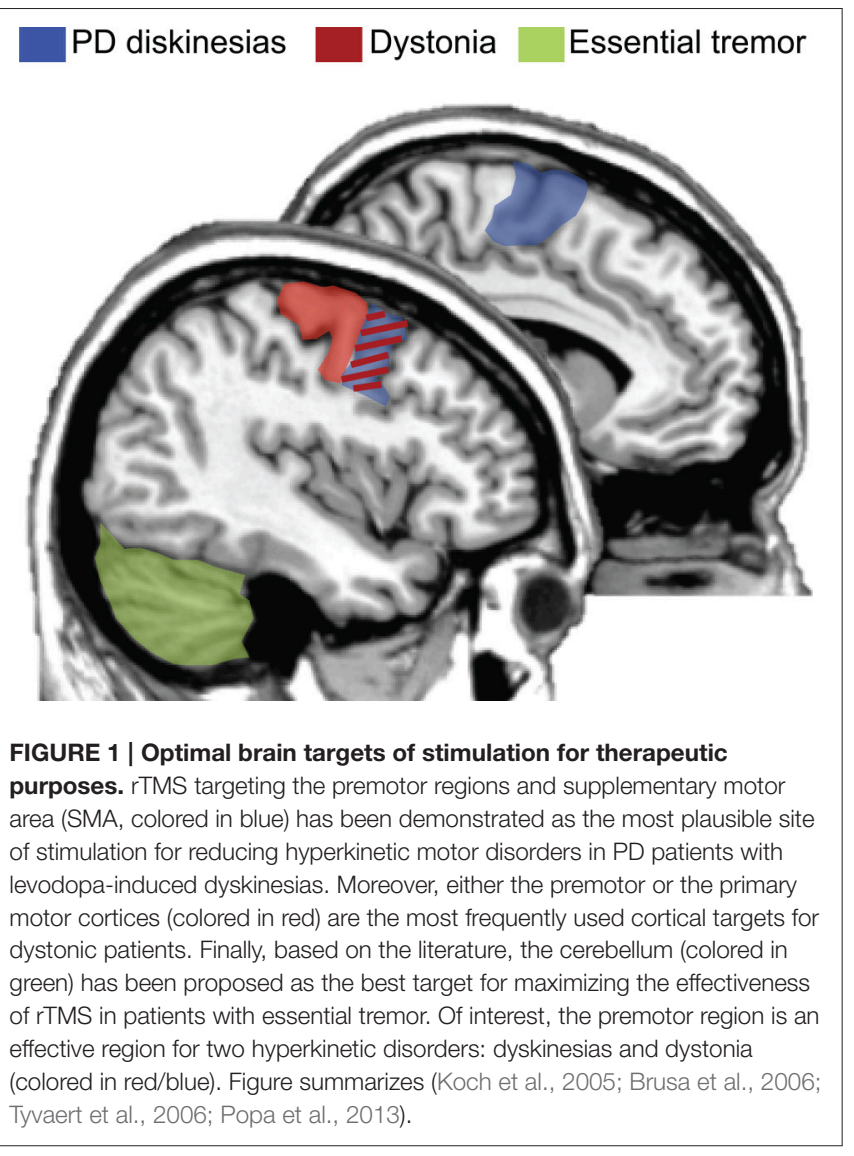

(gray and white matter atrophies) have been found in the wellknown tremor network (Hallett, 2014), as well as in a plethora of other brain regions involving M1, GPi, thalamus, or cerebellum (Passamonti et al., 2011). However, both functional and structural imaging studies reported convergent findings about the role of the cerebellum as the most consistent area of pathology in ET. This hypothesis has also been confirmed by recent post-mortem studies (Louis et al., 2007, 2011) where it was demonstrated that the average amount of cerebellar Purkinje cells is reduced 25\% in tremor patients compared to controls.

Either motor or cerebellum regions are the main target regions to use in neuromodulation for ET. This is mainly guided following results from cortical infarction over motor regions, in which ET motor signs disappeared (Le Pira et al., 2004; Kim et al., 2006). Similarly, single magnetic pulses over M1 seemed to modulate postural tremor in PD patients (Pascual-Leone et al., 1994). These results are in part explained by the correlated frequencies in hand tremor and cortical activity (Hellwig et al., 2001). Yet, rTMS studies trying to apply long-lasting modulatory stimulation in ET have focused over cerebellum and M1 (Gironell et al., 2002, 2014; Avanzino et al., 2009; Hellriegel et al., 2012; Popa et al., 2013; Chuang et al., 2014).

Overall, four studies reported positive anti-tremoric effects using prolonged sessions of rTMS, for a time-period of 3 weeks in ET patients refractory to medical treatment (see Table 3). Beneficial clinical effects assessed by a tremor rating scale (FahnTolosa-Marin tremor scale) were shown as acute and lasting reductions in tremor amplitude and substantial improvement in functional disability (drawing, writing) after rTMS (Popa et al., 2013). Moreover, baseline functional connectivity showed impaired activity in the cerebello-thalamic-cortical loop, a dysfunction that was reset back to near normal levels after rTMS (Popa et al., 2013). The lack of a sham group leaves their results as pending to rule out possible placebo effects.

Historically, the first rTMS application on ET patients was performed by Gironell et al. (2002), who reported acute positive effects after a single session of $1 \mathrm{~Hz}$ rTMS over the cerebellum. The study was double blind, crossover, and placebo-controlled design. Their results were significant just in acute evaluation on subjective assessments performed by patients. The nature of their study was exploratory with limited sample size and makes results hard to interpret due to its moderate and transient effects. Next, a second study (Avanzino et al., 2009) using a single session of unilateral $1 \mathrm{~Hz}$ cerebellar TMS stimulation, also reported a transient improvement in motor scores evaluated using a tapping task. However, no translational results into clinical scores were found. By contrast, inhibitory cTBS of the left primary motor hand area for 2 consecutive days yielded significant motor benefits by reducing tremor total power, assessed with an accelerometer (Hellriegel et al., 2012). Similarly, Chuang et al. (2014) were interested to alter motor cortical dysfunction in ET by applying cTBS over the primary motor and premotor cortices. They found that cTBS was capable of producing a suppressive effect on motor cortical excitability in ET patients, but the effects lasted for a significantly shorter time compared with the effect produced in healthy individuals. Clinically speaking, tremor amplitude was decreased significantly after cTBS but the tremor frequency remained unchanged. The authors concluded that inhibitory circuits within the motor cortex are aberrant and less modifiable in ET patients.

Mechanistically, cerebellar rTMS seems to turn back-tonormal the altered activity in tremor by re-establishing an appropriate synaptic plasticity involved in programming of motor plans (Ito, 2008), resulting in the most plausible candidate target for ET. It turns, thus, possible to boost tremor sign reduction using rTMS protocols with bilateral cerebellar stimulation and low frequency types under multiple rTMS sessions.

\section{CONCLUSIONS}

The results of this systematic review show that there was not a clear consensus on optimal protocols to be used for these motor disorders. Future studies are key to consolidate the use of rTMS in this clinical context in order to reduce hyperkinetic brain dysfunctions. However, some positive results give clinical researchers hints of effective neuromodulatory paradigms and uses. Beneficial effects will most likely be boosted if: (i) prolonged sessions are possible, (ii) the use of low frequency rTMS (i.e., $1 \mathrm{~Hz}$ ), (iii) samples selection restricted to those patients refractory to regular medical treatment, and (iv) choosing the adequate target based on known cortical regions altered in pathophysiological models. Figure 1 represents a summary of candidate regions for treating hyperkinetic dysfunction based on 
the present literature. Optimal cortical regions that have been demonstrated to maximize the effectiveness of rTMS protocols are: (i) the premotor cortex and SMA for dyskinesias in PD; (ii) the motor and premotor cortices for dystonic patients; and (iii) the cerebellum for patients with ET.

Still, basic procedures or techniques, such as cTBS in tremor or combined therapies (different motor rehabilitation programs and rTMS) have not yet been applied in these disorders. Also, if rTMS protocols are used with patient samples grouped by disease onset and symptom type we may expand knowledge on patientdependent states and how TMS may modulate differently at each disease stage or symptomatology.

The reader should also note that in this review we neglected some other important hyperkinetic movement disorders such as, Huntington's disease and Tourette syndrome. With respect to Huntington's disease where the application of rTMS for therapeutic purpose is in its relative infancy (Berardelli and Suppa, 2013; Philpott et al., 2013), the large amount of works

\section{REFERENCES}

Alexander, G. E., DeLong, M. R., and Strick, P. L. (1986). Parallel organization of functionally segregated circuits linking the basal ganglia and cortex. Ann. Rev. Neurosci. 9, 357-381. doi: 10.1146/annurev.ne.09.030186.002041

Allam, N., Brasil-Neto, J. P., Brandão, P., Weiler, F., Barros Filho, J. d., and Tomaz, C. (2007). Relief of primary cervical dystonia symptoms by low frequency transcranial magnetic stimulation of the premotor cortex: case report. Arq. Neuropsiquiatr. 65, 697-699. doi: 10.1590/S0004-282X2007000 400030

Angelakis, E., Liouta, E., Andreadis, N., Leonardos, A., Ktonas, P., Stavrinou, L. C., et al. (2013). Transcranial alternating current stimulation reduces symptoms in intractable idiopathic cervical dystonia: a case study. Neurosci. Lett. 533, 39-43. doi: 10.1016/j.neulet.2012.11.007

Avanzino, L., Bove, M., Tacchino, A., Ruggeri, P., Giannini, A., Trompetto, C., et al. (2009). Cerebellar involvement in timing accuracy of rhythmic finger movements in essential tremor. Eur. J. Neurosci. 30, 1971-1979. doi: 10.1111/j.1460-9568.2009.06984.x

Bäumer, T., Demiralay, C., Hidding, U., Bikmullina, R., Helmich, R. C., Wunderlich, S., et al. (2007). Abnormal plasticity of the sensorimotor cortex to slow repetitive transcranial magnetic stimulation in patients with writer's cramp. Mov. Disord. 22, 81-90. doi: 10.1002/mds.21219

Bäumer, T., Lange, R., Liepert, J., Weiller, C., Siebner, H. R., Rothwell, J. C., et al. (2003). Repeated premotor rTMS leads to cumulative plastic changes of motor cortex excitability in humans. Neuroimage 20, 550-560. doi: 10.1016/S10538119(03)00310-0

Benninger, D. H., Lomarev, M., Lopez, G., Pal, N., Luckenbaugh, D. A., and Hallett, M. (2011). Transcranial direct current stimulation for the treatment of focal hand dystonia. Mov. Disord. 26, 1698-1702. doi: 10.1002/mds.23691

Berardelli, A., Rothwell, J. C., Hallett, M., Thompson, P. D., Manfredi, M., and Marsden, C. D. (1998). The pathophysiology of primary dystonia. Brain 121(Pt 7), 1195-1212. doi: 10.1093/brain/121.7.1195

Berardelli, A., and Suppa, A. (2013). Noninvasive brain stimulation in Huntington's disease. Handb. Clin. Neurol. 116, 555-560. doi: 10.1016/B9780-444-53497-2.00044-9

Berman, B. D., Hallett, M., Herscovitch, P., and Simonyan, K. (2013). Striatal dopaminergic dysfunction at rest and during task performance in writer's cramp. Brain 136, 3645-3658. doi: 10.1093/brain/awt282

Bharath, R. D., Biswal, B. B., Bhaskar, M. V., Gohel, S., Jhunjhunwala, K., Panda, R., et al. (2015). Repetitive transcranial magnetic stimulation induced modulations of resting state motor connectivity in writer's cramp. Eur. J. Neurol. 22, 796-805; e53-e54. doi: 10.1111/ene.12653

Bloch, Y., Arad, S., and Levkovitz, Y. (2014). Deep TMS add-on treatment for intractable tourette syndrome: a feasibility study. World J. Biol. Psychiatry 24, 1-5. doi: $10.3109 / 15622975.2014 .964767$ in psychiatric realm supported the notion that non-invasive brain stimulation is widely recognized as a alternative nonpharmacological approach for decreasing the frequency and intensity of tics in patients with Tourette syndrome (Bloch et al., 2014).

To sum up, the current literature on therapeutic trials of rTMS in hyperkinetic movement disorders patients is still ambiguous, and there is need of well-controlled multicenter randomized clinical trials to define the most effective protocol. However, advancements in technology, as well as, in pathophysiological understanding will improve the effectiveness of this safe and potentially therapeutic option in hyperkinetic movement disorder patients.

\section{AUTHOR CONTRIBUTIONS}

IO designed and wrote the manuscript. AC designed and wrote the manuscript. AQ wrote the manuscript

Borich, M., Arora, S., and Kimberley, T. J. (2009). Lasting effects of repeated rTMS application in focal hand dystonia. Restor. Neurol. Neurosci. 27, 55-65. doi: 10.3233/RNN-2009-0461

Bragg, D. C., Armata, I. A., Nery, F. C., Breakefield, X. O., and Sharma, N. (2011). Molecular pathways in dystonia. Neurobiol. Dis. 42, 136-147. doi: 10.1016/j.nbd.2010.11.015

Breakefield, X. O., Blood, A. J., Li, Y., Hallett, M., Hanson, P. I., and Standaert, D. G. (2008). The pathophysiological basis of dystonias. Nat. Rev. Neurosci. 9 , 222-234. doi: 10.1038/nrn2337

Brighina, F., Romano, M., Giglia, G., Saia, V., Puma, A., Giglia, F., et al. (2009). Effects of cerebellar TMS on motor cortex of patients with focal dystonia: a preliminary report. Exp. Brain Res. 192, 651-656. doi: 10.1007/s00221-0081572-9

Brooks, D. J., Piccini, P., Turjanski, N., and Samuel, M. (2000). Neuroimaging of dyskinesia. Ann. Neurol. 47, S154-S158. discussion: S158-S159.

Brusa, L., Versace, V., Koch, G., Iani, C., Stanzione, P., Bernardi, G., et al. (2006). Low frequency rTMS of the SMA transiently ameliorates peakdose LID in Parkinson's disease. Clin. Neurophysiol. 117, 1917-1921. doi: 10.1016/j.clinph.2006.03.033

Butterworth, S., Francis, S., Kelly, E., McGlone, F., Bowtell, R., and Sawle, G., V (2003). Abnormal cortical sensory activation in dystonia: an fMRI study. Mov. Disord. 18, 673-682. doi: 10.1002/mds. 10416

Cerasa, A., Fasano, A., Morgante, F., Koch, G., and Quattrone, A. (2014). Maladaptive plasticity in levodopa-induced dyskinesias and tardive dyskinesias: old and new insights on the effects of dopamine receptor pharmacology. Front. Neurol. 5:49. doi: 10.3389/fneur.2014.00049

Cerasa, A., Koch, G., Donzuso, G., Mangone, G., Morelli, M., Brusa, L., et al. (2015). A network centred on the inferior frontal cortex is critically involved in levodopa-induced dyskinesias. Brain 138, 414-427. doi: 10.1093/brain/awu329

Cerasa, A., Messina, D., Pugliese, P., Morelli, M., Lanza, P., Salsone, M. et al. (2011). Increased prefrontal volume in PD with levodopa-induced dyskinesias: a voxel-based morphometry study. Mov. Disord. 26, 807-812. doi: $10.1002 / \mathrm{mds} .23660$

Cerasa, A., Morelli, M., Augimeri, A., Salsone, M., Novellino, F., Gioia, M. C., et al. (2013a). Prefrontal thickening in PD with levodopa-induced dyskinesias: new evidence from cortical thickness measurement. Parkinsonism Relat. Disord. 19, 123-125. doi: 10.1016/j.parkreldis.2012.06.003

Cerasa, A., Pugliese, P., Messina, D., Morelli, M., Gioia, M. C., Salsone, M., et al. (2012). Prefrontal alterations in Parkinson's disease with levodopa-induced dyskinesia during fMRI motor task. Mov. Disord. 27, 364-371. doi: $10.1002 / \mathrm{mds} .24017$

Cerasa, A., and Quattrone, A. (2014a). May hyperdirect pathway be a plausible neural substrate for understanding the rTMS-related effects on PD patients with levodopa-induced dyskinesias? Brain Stimul. 7, 488-489. doi: 10.1016/j.brs.2014.01.007 
Cerasa, A., and Quattrone, A. (2014b). May stimulation of the pre-SMA become a new therapeutic target for PD patients with levodopa-induced dyskinesias? Brain Stimul. 7, 335-336. doi: 10.1016/j.brs.2013.12.003

Cerasa, A., Salsone, M., Morelli, M., Pugliese, P., Arabia, G., Gioia, C. M., et al. (2013b). Age at onset influences neurodegenerative processes underlying PD with levodopa-induced dyskinesias. Parkinsonism Relat. Disord. 19, 883-888. doi: 10.1016/j.parkreldis.2013.05.015

Chuang, W.-L., Huang, Y.-Z., Lu, C.-S., and Chen, R.-S. (2014). Reduced cortical plasticity and GABAergic modulation in essential tremor. Mov. Disord. 29, 501-507. doi: $10.1002 / \mathrm{mds} .25809$

Detante, O., Vercueil, L., Thobois, S., Broussolle, E., Costes, N., Lavenne, F., et al. (2004). Globus pallidus internus stimulation in primary generalized dystonia: a H215O PET study. Brain 127, 1899-1908. doi: 10.1093/brain/awh213

Diamond, A., and Jankovic, J. (2005). The effect of deep brain stimulation on quality of life in movement disorders. J. Neurol. Neurosurg. Psychiatry 76, 1188-1193. doi: 10.1136/jnnp.2005.065334

Draganski, B., Thun-Hohenstein, C., Bogdahn, U., Winkler, J., and May, A. (2003). "Motor circuit" gray matter changes in idiopathic cervical dystonia. Neurology 61, 1228-1231. doi: 10.1212/01.WNL.0000094240.93745.83

Edwards, M. J., Talelli, P., and Rothwell, J. C. (2008). Clinical applications of transcranial magnetic stimulation in patients with movement disorders. Lancet Neurol. 7, 827-840. doi: 10.1016/S1474-4422(08)70190-X

Eidelberg, D., Moeller, J. R., Ishikawa, T., Dhawan, V., Spetsieris, P., Przedborski, S., et al. (1995). The metabolic topography of idiopathic torsion dystonia. Brain 118(Pt 6), 1473-1484. doi: 10.1093/brain/118.6.1473

Elahi, B., Elahi, B., and Chen, R. (2009). Effect of transcranial magnetic stimulation on Parkinson motor function-systematic review of controlled clinical trials. Mov. Disord. 24, 357-363. doi: 10.1002/mds.22364

Fasano, A., and Lozano, A. M. (2015). Deep brain stimulation for movement disorders: 2015 and beyond. Curr. Opin. Neurol. 28, 423-436. doi: 10.1097/WCO.0000000000000226

Filipović, S. R., Bhatia, K. P., and Rothwell, J. C. (2013). 1-Hz repetitive transcranial magnetic stimulation and diphasic dyskinesia in Parkinson's disease. Mov. Disord. 28, 245-246. doi: 10.1002/mds.25261

Filipovic, S. R., Rothwell, J. C., van de Warrenburg, B. P., and Bhatia, K. (2009). Repetitive transcranial magnetic stimulation for levodopa-induced dyskinesias in Parkinson's disease. Mov. Disord. 24, 246-253. doi: 10.1002/mds.22348

Furuya, S., Nitsche, M. A., Paulus, W., and Altenmüller, E. (2014). Surmounting retraining limits in Musicians' dystonia by transcranial stimulation. Ann. Neurol. 75, 700-707. doi: 10.1002/ana.24151

George, M. S., Taylor, J. J., and Short, E. B. (2013). The expanding evidence base for rTMS treatment of depression. Curr. Opin. Psychiatry 26, 13-18. doi: 10.1097/YCO.0b013e32835ab46d

Gironell, A., Aguilar, S., Torres, V., and Pagonabarraga, J. (2014). Transcranial direct current stimulation of the cerebellum in essential tremor?: a controlled study deep transcranial magnetic stimulation in a woman with chronic tinnitus?: clinical and fMRI findings. seeking relief from a symptom and finding vivid memor. BRS 7, 491-492. doi: 10.1016/j.brs.2014.02.001

Gironell, A., Kulisevsky, J., Lorenzo, J., Barbanoj, M., Pascual-Sedano, B., and Otermin, P. (2002). Transcranial magnetic stimulation of the cerebellum in essential tremor: a controlled study. Arch. Neurol. 59, 413-417. doi: 10.1001/archneur.59.3.413

Hallett, M. (2014). Tremor: pathophysiology. Parkinsonism Relat. Disord. 20(Suppl. 1), S118-S122. doi: 10.1016/S1353-8020(13)70029-4

Hamani, C., Saint-Cyr, J. A., Fraser, J., Kaplitt, M., and Lozano, A. M. (2004). The subthalamic nucleus in the context of movement disorders. Brain 127, 4-20. doi: 10.1093/brain/awh029

Havrankova, P., Jech, R., Walker, N. D., Operto, G., Tauchmanova, J., Vymazal, J., et al. (2010). Repetitive TMS of the somatosensory cortex improves writer's cramp and enhances cortical activity. Neuro Endocrinol. Lett. 31, 73-86.

Hellriegel, H., Schulz, E. M., Siebner, H. R., Deuschl, G., and Raethjen, J. H. (2012). Continuous theta-burst stimulation of the primary motor cortex in essential tremor. Clin. Neurophysiol. 123, 1010-1015. doi: 10.1016/j.clinph.2011.08.033

Hellwig, B., Häussler, S., Schelter, B., Lauk, M., Guschlbauer, B., Timmer, J., et al. (2001). Tremor-correlated cortical activity in essential tremor. Lancet 357, 519-523. doi: 10.1016/S0140-6736(00)04044-7

Helmich, R. C., Toni, I., Deuschl, G., and Bloem, B. R. (2013). The pathophysiology of essential tremor and parkinson's tremor. Curr. Neurol. Neurosci. Rep. 13:378. doi: 10.1007/s11910-013-0378-8
Herz, D. M., Haagensen, B. N., Christensen, M. S., Madsen, K. H., Rowe, J. B., Løkkegaard, A., et al. (2014). The acute brain response to levodopa heralds dyskinesias in Parkinson disease. Ann. Neurol. 75, 829-836. doi: 10.1002/ana.24138

Herz, D. M., Haagensen, B. N., Christensen, M. S., Madsen, K. H., Rowe, J. B., Løkkegaard, A., et al. (2015). Abnormal dopaminergic modulation of striatocortical networks underlies levodopa-induced dyskinesias in humans. Brain 138, 1658-1666. doi: 10.1093/brain/awv096

Huang, Y. Z., Edwards, M. J., Rounis, E., Bhatia, K. P., and Rothwell, J. C. (2005). Theta burst stimulation of the human motor cortex. Neuron 45, 201-206. doi: 10.1016/j.neuron.2004.12.033

Huang, Y. Z., Rothwell, J. C., Lu, C. S., Wang, J., and Chen, R. S. (2011). Restoration of motor inhibition through an abnormal premotormotor connection in dystonia. Mov. Disord. 25, 696-703. doi: 10.1002/mds. 22814

Iacono, D., Geraci-Erck, M., Peng, H., Rabin, M. L., and Kurlan, R. (2015). Reduced number of pigmented neurons in the substantia nigra of dystonia patients? Findings from extensive neuropathologic, immunohistochemistry, and quantitative analyses. Tremor Other Hyperkinet. Mov. (N.Y). 5:tre-5-301. doi: 10.7916/D8T72G9G

Ibáñez, V., Sadato, N., Karp, B., Deiber, M. P., and Hallett, M. (1999). Deficient activation of the motor cortical network in patients with writer's cramp. Neurology 53, 96-105.

Ito, M. (2008). Control of mental activities by internal models in the cerebellum. Nat. Rev. Neurosci. 9, 304-313. doi: 10.1038/nrn2332

Kehagia, A. A., Barker, R. A., and Robbins, T. W. (2013). Cognitive impairment in Parkinson's disease: the dual syndrome hypothesis. Neurodegener. Dis. 11, 79-92. doi: 10.1159/000341998

Kim, J.-S., Park, J.-W., Kim, W.-J., Kim, H.-T., Kim, Y.-I., and Lee, K.-S. (2006), Disappearance of essential tremor after frontal cortical infarct. Mov. Disord. 21, 1284-1285. doi: $10.1002 / \mathrm{mds} .20894$

Kimberley, T. J., Borich, M. R., Arora, S., and Siebner, H. R. (2013). Multiple sessions of low-frequency repetitive transcranial magnetic stimulation in focal hand dystonia: Clinical and physiological effects. Restor. Neurol. Neurosci. 31, 533-542. doi: 10.3233/RNN-120259

Koch, G. (2013). Do studies on cortical plasticity provide a rationale for using noninvasive brain stimulation as a treatment for Parkinson's disease patients? Front. Neurol. 4:180. doi: 10.3389/fneur.2013.00180

Koch, G., Brusa, L., Caltagirone, C., Peppe, A., Oliveri, M., Stanzione, P., et al. (2005). rTMS of supplementary motor area modulates therapyinduced dyskinesias in Parkinson disease. Neurology 65, 623-625. doi: 10.1212/01.wnl.0000172861.36430.95

Koch, G., Brusa, L., Carrillo, F., Lo Gerfo, E., Torriero, S., Oliveri, M., et al. (2009). Cerebellar magnetic stimulation decreases levodopainduced dyskinesias in Parkinson disease. Neurology 73, 113-119. doi: 10.1212/WNL.0b013e3181ad5387

Koch, G., Porcacchia, P., Ponzo, V., Carrillo, F., Cáceres-Redondo, M. T., Brusa, L., et al. (2014). Effects of two weeks of cerebellar theta burst stimulation in cervical dystonia patients. Brain Stimul. 7, 564-572. doi: 10.1016/j.brs.2014. 05.002

Kodama, M., Kasahara, T., Hyodo, M., Aono, K., Sugaya, M., Koyama, Y., et al. (2011). Effect of low-frequency repetitive transcranial magnetic stimulation combined with physical therapy on L-dopa-induced painful off-period dystonia in Parkinson's disease. Am. J. Phys. Med. Rehabil. 90, 150-155. doi: 10.1097/PHM.0b013e3181fc7ccd

Le Pira, F., Giuffrida, S., Panetta, M. R., Lo Bartolo, M. L., and Politi, G. (2004). Selective disappearance of essential tremor after ischaemic stroke. Eur. J. Neurol. 11, 422-423. doi: 10.1111/j.1468-1331.2004.00824.x

Lefaucheur, J. P., Drouot, X., Von Raison, F., Ménard-Lefaucheur, I., Cesaro, P., and Nguyen, J. P. (2004). Improvement of motor performance and modulation of cortical excitability by repetitive transcranial magnetic stimulation of the motor cortex in Parkinson's disease. Clin. Neurophysiol. 115, 2530-2541. doi: 10.1016/j.clinph.2004.05.025

Lehéricy, S., Tijssen, M. A. J., Vidailhet, M., Kaji, R., and Meunier, S. (2013). The anatomical basis of dystonia: current view using neuroimaging. Mov. Disord. 28, 944-957. doi: $10.1002 / \mathrm{mds} .25527$

Lerner, A., Shill, H., Hanakawa, T., Bushara, K., Goldfine, A., and Hallett, M. (2004). Regional cerebral blood flow correlates of the severity of writer's cramp symptoms. Neuroimage 21, 904-913. doi: 10.1016/j.neuroimage.2003.10.019 
Louis, E. D. (2015). Medication non-adherence in essential tremor. Parkinsonism Relat. Disord. 21, 138-141. doi: 10.1016/j.parkreldis.2014.12.001

Louis, E. D., Asabere, N., Agnew, A., Moskowitz, C. B., Lawton, A., Cortes, E., et al. (2011). Rest tremor in advanced essential tremor: a post-mortem study of nine cases. J. Neurol. Neurosurg. Psychiatry 82, 261-265. doi: 10.1136/jnnp.2010.215681

Louis, E. D., Faust, P. L., Vonsattel, J.-P. G., Honig, L. S., Rajput, A., Robinson, C. A., et al. (2007). Neuropathological changes in essential tremor: 33 cases compared with 21 controls. Brain 130, 3297-3307. doi: 10.1093/brain/awm266

Marsden, C. D. (1976). Dystonia: the spectrum of the disease. Res. Publ. Assoc. Res. Nerv. Ment. Dis. 55, 351-367.

Marsden, C. D., Obeso, J. A., Zarranz, J. J., and Lang, A. E. (1985). The anatomical basis of symptomatic hemidystonia. Brain 108(Pt 2), 463-483. doi: 10.1093/brain/108.2.463

Middleton, F. A., and Strick, P. L. (2000). Basal ganglia output and cognition: evidence from anatomical, behavioral, and clinical studies. Brain Cogn. 42, 183-200. doi: 10.1006/brcg.1999.1099

Murase, N., Rothwell, J. C., Kaji, R., Urushihara, R., Nakamura, K., Murayama, $\mathrm{N}$., et al. (2005). Subthreshold low-frequency repetitive transcranial magnetic stimulation over the premotor cortex modulates writer's cramp. Brain 128, 104-115. doi: 10.1093/brain/awh315

Neumann, W.-J., Jha, A., Bock, A., Huebl, J., Horn, A., Schneider, G.-H., et al. (2015). Cortico-pallidal oscillatory connectivity in patients with dystonia. Brain 138, 1894-1906. doi: 10.1093/brain/awv109

Obeso, I., Cho, S. S., Antonelli, F., Houle, S., Jahanshahi, M., Ko, J. H., et al. (2013). Stimulation of the pre-SMA influences cerebral blood flow in frontal areas involved with inhibitory control of action. Brain Stimul. 6, 769-776. doi: 10.1016/j.brs.2013.02.002

Obeso, I., and Strafella, A. P. (2014a). Boosting response inhibition neural network with rTMS may improve dyskinesias in Parkinson's disease. Brain Stimul. 7, 336-337. doi: 10.1016/j.brs.2013.12.004

Obeso, I., and Strafella, A. P. (2014b). Top-down control of dyskinesias in PD using brain stimulation. Brain Stimul. 7, 488. doi: 10.1016/j.brs.2014.01.005

Obeso, J. A., Rodriguez-Oroz, M. C., Rodriguez, M., DeLong, M. R., and Olanow, C. W. (2000). Pathophysiology of levodopa-induced dyskinesias in Parkinson's disease: problems with the current model. Ann. Neurol. 47(4 Suppl.), S22-S32. discussion: S32-S34.

Odergren, T., Stone-Elander, S., and Ingvar, M. (1998). Cerebral and cerebellar activation in correlation to the action-induced dystonia in writer's cramp. Mov. Disord. 13, 497-508. doi: 10.1002/mds.870130321

Oga, T., Honda, M., Toma, K., Murase, N., Okada, T., Hanakawa, T., et al. (2002). Abnormal cortical mechanisms of voluntary muscle relaxation in patients with writer's cramp: an fMRI study. Brain 125, 895-903. doi: 10.1093/brain/awf083

Otsuka, M., Ichiya, Y., Shima, F., Kuwabara, Y., Sasaki, M., Fukumura, T., et al. (1992). Increased striatal 18F-dopa uptake and normal glucose metabolism in idiopathic dystonia syndrome. J. Neurol. Sci. 111, 195-199. doi: 10.1016/0022$510 \mathrm{X}(92) 90068-\mathrm{V}$

Pascual-Leone, A., Valls-Solé, J., Toro, C., Wassermann, E. M., and Hallett, M. (1994). Resetting of essential tremor and postural tremor in Parkinson's disease with transcranial magnetic stimulation. Muscle Nerve 17, 800-807. doi: $10.1002 /$ mus. 880170716

Passamonti, L., Novellino, F., Cerasa, A., Chiriaco, C., Rocca, F., Matina, M. S., et al. (2011). Altered cortical-cerebellar circuits during verbal working memory in essential tremor. Brain 134, 2274-2286. doi: 10.1093/brain/awr164

Philpott, A. L., Fitzgerald, P. B., Cummins, T. D., and Georgiou-Karistianis, N. (2013). Transcranial magnetic stimulation as a tool for understanding neurophysiology in Huntington's disease: a review. Neurosci. Biobehav. Rev. 37, 1420-1433. doi: 10.1016/j.neubiorev.2013.05.009

Picazio, S., and Koch, G. (2015). Is motor inhibition mediated by cerebello-cortical interactions? Cerebellum 14, 47-49. doi: 10.1007/s12311-014-0609-9

Pinto, A. D., Lang, A. E., and Chen, R. (2003). The cerebellothalamocortical pathway in essential tremor. Neurology 60, 1985-1987. doi: 10.1212/ 01.WNL.0000065890.75790.29

Popa, T., Russo, M., Vidailhet, M., Roze, E., and Lehéricy, S. (2013). Brain Stimulation Cerebellar rTMS stimulation may induce prolonged clinical bene fi ts in essential tremor, and subjacent changes in functional connectivity?: an open label trial. Brain Stimul. 6, 175-179. doi: 10.1016/j.brs.2012.04.009

Pujol, J., Roset-Llobet, J., Rosinés-Cubells, D., Deus, J., Narberhaus, B., VallsSolé, J., et al. (2000). Brain cortical activation during guitar-induced hand dystonia studied by functional MRI. Neuroimage 12, 257-267. doi: 10.1006/nimg.2000.0615

Rascol, O., Sabatini, U., Brefel, C., Fabre, N., Rai, S., Senard, J. M., et al. (1998). Cortical motor overactivation in parkinsonian patients with L-dopa-induced peak-dose dyskinesia. Brain 121(Pt 3), 527-533. doi: 10.1093/brain/121.3.527

Ridding, M. C., and Rothwell, J. C. (2007). Is there a future for therapeutic use of transcranial magnetic stimulation? Nat. Rev. Neurosci. 8, 559-567. doi: 10.1038/nrn2169

Rothwell, J. C., and Obeso, J. A. (2015). Can levodopa-induced dyskinesias go beyond the motor circuit? Brain 138, 242-244. doi: 10.1093/brain/ awu365

Sadnicka, A., Hamada, M., Bhatia, K. P., Rothwell, J. C., and Edwards, M. J. (2014). Cerebellar stimulation fails to modulate motor cortex plasticity in writing dystonia. Mov. Disord. 29, 1304-1307. doi: 10.1002/mds.25881

Sandvik, U., Koskinen, L.-O., Lundquist, A., and Blomstedt, P. (2012). Thalamic and subthalamic deep brain stimulation for essential tremor: where is the optimal target? Neurosurgery 70, 840-5. discussion: 845-846. doi: 10.1227/NEU.0b013e318236a809

Schneider, S. A., Pleger, B., Draganski, B., Cordivari, C., Rothwell, J. C., Bhatia, K. P., et al. (2010). Modulatory effects of $5 \mathrm{~Hz}$ rTMS over the primary somatosensory cortex in focal dystonia - An fMRI-TMS Study. Mov. Disord. 25, 76-83. doi: $10.1002 / \mathrm{mds} .22825$

Siebner, H. R., Tormos, J. M., Ceballos-Baumann, A. O., Auer, C., Catala, M. D., Conrad, B., et al. (1999). Low-frequency repetitive transcranial magnetic stimulation of the motor cortex in writer's cramp. Neurology 52, 529-537. doi: 10.1212/WNL.52.3.529

Tyvaert, L., Houdayer, E., Devanne, H., Monaca, C., Cassim, F., and Derambure, P. (2006). The effect of repetitive transcranial magnetic stimulation on dystonia: a clinical and pathophysiological approach. Neurophysiol. Clin. 36, 135-143. doi: 10.1016/j.neucli.2006.08.007

Vernon, A. C., and Modo, M. (2012). Do levodopa treatments modify the morphology of the parkinsonian brain? Mov. Disord. 27, 166-167. doi: $10.1002 / \mathrm{mds} .24018$

Vidailhet, M., Vercueil, L., Houeto, J.-L., Krystkowiak, P., Benabid, A.-L., Cornu, P., et al. (2005). Bilateral deep-brain stimulation of the globus pallidus in primary generalized dystonia. N. Engl. J. Med. 352, 459-467. doi: 10.1056/NEJMoa042187

Vitek, J. L., Chockkan, V., Zhang, J. Y., Kaneoke, Y., Evatt, M., DeLong, M. R. et al. (1999). Neuronal activity in the basal ganglia in patients with generalized dystonia and hemiballismus. Ann. Neurol. 46, 22-35.

Wagle-Shukla, A., Angel, M. J., Zadikoff, C., Enjati, M., Gunraj, C., Lang, A. E., et al. (2007). Low-frequency repetitive transcranial magnetic stimulation for treatment of levodopa-induced dyskinesias. Neurology 68, 704-705. doi: 10.1212/01.wnl.0000256036.20927.a5

Wu, T., and Hallett, M. (2013). Reply: the cerebellum in Parkinson's disease and parkinsonism in cerebellar disorders. Brain 136:e249. doi: 10.1093/brain/aws360

Zandbelt, B. B., Bloemendaal, M., Hoogendam, J. M., Kahn, R. S., and Vink, M. (2013). Transcranial magnetic stimulation and functional MRI reveal cortical and subcortical interactions during stop-signal response inhibition. J. Cogn. Neurosci. 25, 157-174. doi: 10.1162/jocn_a_00309

Zheng, Z., Pan, P., Wang, W., and Shang, H. (2012). Neural network of primary focal dystonia by an anatomic likelihood estimation meta-analysis of gray matter abnormalities. J. Neurol. Sci. 316, 51-55. doi: 10.1016/j.jns.2012. 01.032

Zhuang, P., Li, Y., and Hallett, M. (2004). Neuronal activity in the basal ganglia and thalamus in patients with dystonia. Clin. Neurophysiol. 115, 2542-2557. doi: 10.1016/j.clinph.2004.06.006

Conflict of Interest Statement: The authors declare that the research was conducted in the absence of any commercial or financial relationships that could be construed as a potential conflict of interest.

Copyright ( 2016 Obeso, Cerasa and Quattrone. This is an open-access article distributed under the terms of the Creative Commons Attribution License (CC BY). The use, distribution or reproduction in other forums is permitted, provided the original author(s) or licensor are credited and that the original publication in this journal is cited, in accordance with accepted academic practice. No use, distribution or reproduction is permitted which does not comply with these terms. 